\title{
Bioinspired Synthesis of Acacia senegal Leaf Extract Functionalized Silver Nanoparticles and Its Antimicrobial Evaluation
}

\author{
Edwina Olohirere Uzunuigbe $\mathbb{D}^{\mathbb{D}},{ }^{1,2}$ Abidemi Paul Kappo, ${ }^{3}$ Sixberth Mlowe $\mathbb{D}^{4,5}$ \\ and Neerish Revaprasadu ${ }^{4}$ \\ ${ }^{1}$ Department of Biochemistry and Microbiology, University of Zululand, Kwadlangezwa 3886, South Africa \\ ${ }^{2}$ Rubber Research Institute of Nigeria, Iyanomo, PMB, 1049 Benin City, Edo State, Nigeria \\ ${ }^{3}$ Department of Biochemistry, University of Johanneburg, Kingsway Campus, Auckland Park, 2006, South Africa \\ ${ }^{4}$ Department of Chemistry, University of Zululand, Kwadlangezwa 3886, South Africa \\ ${ }^{5}$ Department of Chemistry, Dar es Salaam University College of Education, P.O. Box 2329, Dar es Salaam, Tanzania
}

Correspondence should be addressed to Edwina Olohirere Uzunuigbe; uzedwina@gmail.com

Received 25 May 2020; Revised 30 August 2020; Accepted 16 November 2020; Published 29 November 2020

Academic Editor: Domenico Acierno

Copyright (c) 2020 Edwina Olohirere Uzunuigbe et al. This is an open access article distributed under the Creative Commons Attribution License, which permits unrestricted use, distribution, and reproduction in any medium, provided the original work is properly cited.

Synthesizing nanoparticles with the less environmentally malignant approach using plant extract is of great interest; this is because most of the chemical approaches can be very costly, toxic, and time-consuming. Herein, we report the use of Acacia senegal leaf extracts to synthesize silver nanoparticles (AgNPs) using an environmentally greener approach. Silver ions were reduced using the bioactive components of the plant extracts with observable colour change from faint colourless to a brownish solution as indication of AgNP formation. The structural properties of the as-synthesized AgNPs were characterized using powder X-ray diffraction (XRD), transmission electron microscopy (TEM), Fourier transform infrared spectroscopy (FTIR), and UV-Vis absorption spectrum. Antimicrobial assessment of the as-synthesized AgNPs was explored on some strains of gram-positive and gram-negative bacteria. The obtained results indicate that the as-synthesized AgNPs are pure crystallite of cubic phase of AgNPs, fairly dispersed with a size range of 10-19 nm. The AgNPs were found to be small in size and exhibit significant antibacterial activities, suggesting that the as-synthesized AgNPs could be used in the pharmaceutical and food industries as bactericidal agents.

\section{Introduction}

The biosynthetic approach in the use of naturally occurring reducing agents such as plant extracts, biomass, and biological molecules has emerged as a simple alternative method to complex chemical method of nanoparticle synthesis. The use of silver particles in the medicinal field can be traced back to more than ten decades ago when silver was first used in medicine before the discovery of antibiotics [1,2]. Silver nanoparticles are known to have unique properties that make them ideal for various biological and biomedical applications such as in the treatment and prevention of certain diseases, for therapeutic and diagnostic use including biomolecular detection [3-7], and in industry [8]. This is mainly a result of the antimicrobial, antibacterial, antifungal, antiviral, and antiinflammatory capabilities of the AgNPs $[4,6,9,10]$. Silver is additionally known to possess high thermal and electrical conductivity thus resulting in its good optical reflectivity as well as various biological and catalytic abilities $[7,11,12]$, which has, in turn, resulted in its high demand $[13,14]$.

Although the processes involved in nanoparticle synthesis result in particles possessing different anticipated characteristics, the chemical and physical methods which include UV irradiation, lithography, ultrasonic fields, and photochemical 
reduction processes for the production of nanoparticles have their own pitfalls in that they are costly, labour-intensive, and toxic to both organisms and the environment [5, 15-18]. Hence, "green" or biogenic synthesis of nanoparticles is now preferred over physicochemical methods because it not only results in more eco-friendly, cost-effective, contamination-free, and nontoxic sustainable nanoparticles but also allows for higher yield of products with better defined characteristics [12, 19-23]. It has been well documented that living plants and bioactive compounds from their extracts such as polyphenols, phenolic acids or proteins, sugars, terpenoids, and alkaloids have the ability to reduce metal ions by acting as electron shuttles and can therefore be used in the bioreduction of harmful metal ions in the synthesis of nanoparticles $[17,20,22,24,25]$. Numerous plant parts have been shown to be effective in the reduction of $\mathrm{Au}$ and $\mathrm{Ag}$ ions for the formation of gold and silver nanoparticles; these include and not limited to lemon grass leaf extracts (Cymbopogon flexuosus), neem (Azadirachta indica), and tamarind (Tamarindus indica) and fruit extract of amla (Emblica officinalis), as well as the biomass of wheat (Triticum aestivum) and oats (Avena sativa) [26]. Through green synthesis, nanoparticles are synthesized within a short time frame in a single-step bottom-up approach where the use of toxic chemicals, high pressure, energy, or temperatures is taken down to a minimum and plant extracts are used as bioreducing agents and precursors [27, 28]. Plants additionally make the "green" process more favourable and exploitable due to their wide distribution, availability, and costeffectiveness [14, 29]. Moreover, the bioactive compounds in the plant may act as both a reducing and capping agent in nanoparticle synthesis. Synthesis of nanoparticles using extracts from plants can be determined by the phytochemical components of the plant made up of different functional groups [30]. The nature of these phytochemicals can also affect the morphology, size, and shape of nanoparticle synthesized [31].

In this study, silver nanoparticles were synthesized from aqueous leaf extracts of Acacia senegal (Gum Arabic), a plant that grows in a number of sub-Saharan African countries like Sudan, Nigeria, Mauritania, Senegal, Mali, Burkina Faso, Niger, Chad, Cameroon, Somalia, Ethiopia, and Kenya [3234]. This plant is mainly known for the rich gummy exudate produced by its stem and branches, which is a nonviscous liquid rich in soluble fibres [32, 35, 36]. The gum is used in the food and drink industries as a stabilizer, an emulsifier in the production of soft drinks and beer, and gummy candies, as well as in cosmetic and pharmaceutical industries. The bioactive components of the Acacia senegal leaf extracts have been previously analyzed and found to contain compounds like phenols, flavonoid, alkaloid, saponins, tannins, and terpenoids [37]. These compounds are known to act as reducing agents in the synthesis of metal nanoparticles $[38,39]$. Therefore, we used the leaf extracts of the Acacia senegal plant both as reducing and capping agent during the synthesis of silver nanoparticles (AgNPs) in distilled water and the resulting nanoparticles were tested for their antimicrobial activity on selected gram-negative and grampositive bacteria.
TABle 1: Phytochemical screening of Acacia senegal aqueous extract.

\begin{tabular}{lc}
\hline Phytochemicals & Present $(+)$; absent $(-)$ \\
\hline Alkaloids & + \\
Anthraquinones & - \\
Carbohydrates & + \\
Cardiac glycosides & + \\
Flavonoids & + \\
Phenols & + \\
Saponins & + \\
Steroids & + \\
Tannins & + \\
Terpenoids & + \\
\hline
\end{tabular}

\section{Experimental}

2.1. Materials. Silver nitrate (99.2\%) and methanol were purchased from Sigma-Aldrich, USA, and used as received. Acacia senegal leaves were collected from the plantation of the Rubber Research Institute of Nigeria (RRIN), Benin City, Nigeria, with assigned voucher number $\mathrm{UBH}_{\mathrm{A}} 379$ deposited the plant voucher specimen at RRIN Herbarium.

2.2. Preparation of Leaf Extract. Fresh and healthy leaves of Acacia senegal were washed thoroughly in water and airdried for 10 days and then grounded into a fine powder with a kitchen blender. About $10 \mathrm{~g}$ of the fine powder was boiled in $100 \mathrm{~mL}$ distilled water for $10 \mathrm{~min}$ and subsequently filtered after cooling. Analysis of the phytochemical constituents was carried out using the method described by [40,41] using plant water extract to ascertain the presence of bioactive compounds. The phytochemicals shown in Table 1 were present in the aqueous extract of Acacia senegal.

2.3. Synthesis of Silver Nanoparticles. $10 \mathrm{~mL}$ of the obtained leaf extract was added to $90 \mathrm{~mL}$ of $1.0 \mathrm{mM} \mathrm{AgNO}_{3}$, and the mixture was autoclaved for 10 minutes at $121^{\circ} \mathrm{C} 15 \mathrm{psi}$; colour change of the mixture was observed from an initial faint yellow to a brownish-yellow colloidal mixture synthesis. The mixture was washed with methanol twice and finally washed with distilled water several times in a centrifuge at $4400 \mathrm{rpm}$ for $5 \mathrm{~min}$ in each cycle. The as-synthesized AgNPs were dried in ambient temperature.

2.4. Characterization of Silver Nanoparticles. UV-Vis absorption spectra were recorded on a Varian Cary $50 \mathrm{UV} / \mathrm{V}$ is spectrophotometer. Photoluminescence of the particles was analyzed using a PerkinElmer LS55 Luminescence spectrophotometer. FTIR analysis of the samples was carried out using a PerkinElmer FTIR spectrometer in the range of $4000-450 \mathrm{~cm}^{-1}$. TEM analyses were performed using a JEOL 1400 TEM. Samples were prepared by placing a drop of a dilute solution of nanoparticles on Formvar-coated grids (150-mesh) and allowed to dry completely at room temperature and viewed at an accelerating voltage of $100 \mathrm{kV}$. X-ray diffraction (XRD) studies were done with a Bruker AXS D8-Advance diffractometer equipped with nickel-filtered 
$\mathrm{Cu} \mathrm{K} \alpha$ radiation $(\lambda=1.5406 \AA)$ and the $2 \theta$ ranged from 20 $80^{\circ}$ at $40 \mathrm{kV}, 40 \mathrm{~mA}$, and room temperature. A Zeiss Ultra Plus FEG SEM equipped with an Oxford detector EDX at $20 \mathrm{kV}$ which uses Aztec software was used for elemental analysis. The samples were carbon-coated using Quorum coater (Model Q150TE).

\subsection{Antibacterial Studies of Silver Nanoparticles}

2.5.1. Zone of Inhibition. The antimicrobial activity of the AgNPs was evaluated using the disc agar diffusion method [42]. Different bacterial strains were grown at $37^{\circ} \mathrm{C}$ for 24 hours in a $20 \mathrm{~mL}$ nutrient broth; microbial cultures were then diluted to $0.5 \mathrm{McFarland}$ standard. Thereafter, standard petri dishes containing Mueller-Hinton agar were inoculated with bacterial culture. Sterile paper disc $(6 \mathrm{~mm})$ was impregnated with $10 \mu \mathrm{L}(10 \mathrm{mg} / \mathrm{mL}$ in $5 \%$ DMSO $)$ of the test extract and placed on the inoculated plates, which were then incubated at $37^{\circ} \mathrm{C}$ for 24 hours. The next morning, inhibition zones formed around the disc were measured with a transparent ruler in millimetres. This experiment was carried out in triplicates.

2.5.2. Minimum Inhibitory Concentration (MIC) Assay. The microplate broth dilution assay was used to assess the minimal inhibitory concentration of the $A$. senegal plant extract with slight modifications [43]. A 12-hour-old culture was diluted 1:100 with freshly prepared Muller-Hinton broth. Thereafter, about $100 \mu \mathrm{L}$ of extract $(10 \mathrm{mg} / \mathrm{mL}$ in $5 \%$ DMSO) was added to a multiwell plate containing $100 \mu \mathrm{L}$ of freshly prepared broth and serially diluted. The plates were then incubated overnight at $37^{\circ} \mathrm{C}$. Approximately $20 \mu \mathrm{L}$ of $2 \mathrm{mg} / \mathrm{mL}$ freshly prepared iodonitrotetrazolium chloride was added to each well and incubated for 1 hour at the same temperature. The MIC was defined as the lowest concentration of the extract to inhibit bacterial growth.

2.5.3. Minimum Bactericidal Concentration (MBC) Assay. A loop full of the microorganism in the wells showing little or no growth in the MIC assay was selected and subcultured on petri plates containing an agar for different microbes. The MBC was defined as the lowest concentration that showed no bacterial growth in the subcultures [44].

2.5.4. Lactate Dehydrogenase (LDH) Release Assay. Bacteriainduced cell damage was quantified using the method described by [45]. Wells containing cultured cells were inoculated with $40 \mu \mathrm{L}$ of Minimum Essential Media (MEM) or tear fluid containing $10^{6} \mathrm{CFU}$ of cytotoxic bacteria/mL. After 3 hours of incubation at $37^{\circ} \mathrm{C}$, the supernatant from each well was collected and diluted 1:20 with fresh MEM. The quantity of LDH present in the samples was detected by using a cytotoxicity detection kit (Sigma-Aldrich) according to the manufacturer's instructions and expressed as absorbance at $490 \mathrm{~nm}$. An additional two sets of wells were treated with MEM but without bacteria. One set of cells was used to determine background LDH release, while cells in the other group were lysed with MEM containing Triton X-100 (0.25\% v/v) at the end of the assay to determine the amount of $\mathrm{LDH}$ released when $100 \%$ of the cells were killed.

\section{Results and Discussion}

3.1. Optical and Structural Properties of As-Synthesized Silver Nanoparticles Using Acacia senegal Leaf Extract. The biosynthetic approach in the use of naturally occurring reducing agents such as plant extracts, biomass, and biological molecules has emerged as a simple alternative method to complex chemical method of nanoparticle synthesis. Silver nanoparticles have been extensively explored because of their biological and biomedical applications among other functions. Plant extracts are known to contain biomolecules such as phenols, tannins, polysaccharides, saponins, terpenoids, flavonoid, and alkaloids which are well reported to have active reductive potential. Similarly, Acacia senegal leaf extracts are reported to contain compounds like phenols, flavonoid, alkaloid, saponins, tannins, and terpenoids [37]. In this study, the leaves of $A$. senegal were first boiled, filtered, and added to $1.0 \mathrm{mM}$ solution of $\mathrm{AgNO}_{3}$. Silver ions were reduced to silver nanoparticles by the biomolecules present in the Acacia senegal plant extracts $[38,39,46]$. In this study, the colour change was indicative of the bioreduction of silver ion to AgNPs; thus, the plant extracts act as a reducing agent (Figure 1) [47-49]. Usually, the colour changes can vary from plant to plant and method of synthesis $[21,50]$. The biomolecules also act as a stabilizing agent by attaching to the nanoparticles to prevent agglomeration [39].

The UV-Vis spectrum of the as-synthesized AgNPs is presented in Figure 2. The broad peak of the obtained UVVis spectrum indicates the presence of well-dispersed particles. The absorption spectrum of Ag nanoparticles revealed a single broad peak at $467 \mathrm{~nm}$ of the sample obtained within 24 hours of synthesis, and this corresponds to the Surface Plasmon Resonance (SPR) of Ag nanoparticles as observed in other studies [51,52]. Additionally, photoluminescence spectrum depicted in Figure 2 showed an emission peak at $437 \mathrm{~nm}$, which is blue shifted when compared to the corresponding absorption spectrum and this corroborates with previous literature [53].

Figure 3 shows representative transmission electron microscopy (TEM) images of silver nanoparticles obtained using $A$. senegal leaf extract. The images revealed that the as-synthesized silver nanoparticles are loosely aggregated and close to spherical in shape with sizes ranging from $10 \mathrm{~nm}$ to $19 \mathrm{~nm}$. The elemental composition of the obtained silver nanoparticles was confirmed by EDX.

Powder X-ray diffraction ( $\mathrm{p}$-XRD) analysis was used to describe the crystallinity of the as-obtained silver nanoparticles synthesized using A. senegal leaf extract. The cubic phase (JCPDS card number: 01-087-0719) of silver nanoparticles was confirmed with diffraction peaks at $2 \theta$ values of $38.36^{\circ}$, $44.55^{\circ}, 64.69^{\circ}$, and $77.76^{\circ}$ corresponding to (111), (200), (220), and (311) mirror planes (Figure 4). No secondary phase of silver oxide was detected. The sharpness of the XRD patterns or peaks shows that the AgNPs are free of impurities. The crystallite size of $12.82 \mathrm{~nm}$ was also calculated using the Scherrer equation; particle size $(S)=B \Lambda / \beta$ $\cos \theta$, where $S$ is the size of particles $(\mathrm{nm}), \lambda=1.5406 \AA$ is a wavelength of the $\mathrm{X}$-ray radiation, $B=0.91, \beta$ is full width at half maximum (FWHM) of the XRD pattern, and $\theta$ is 


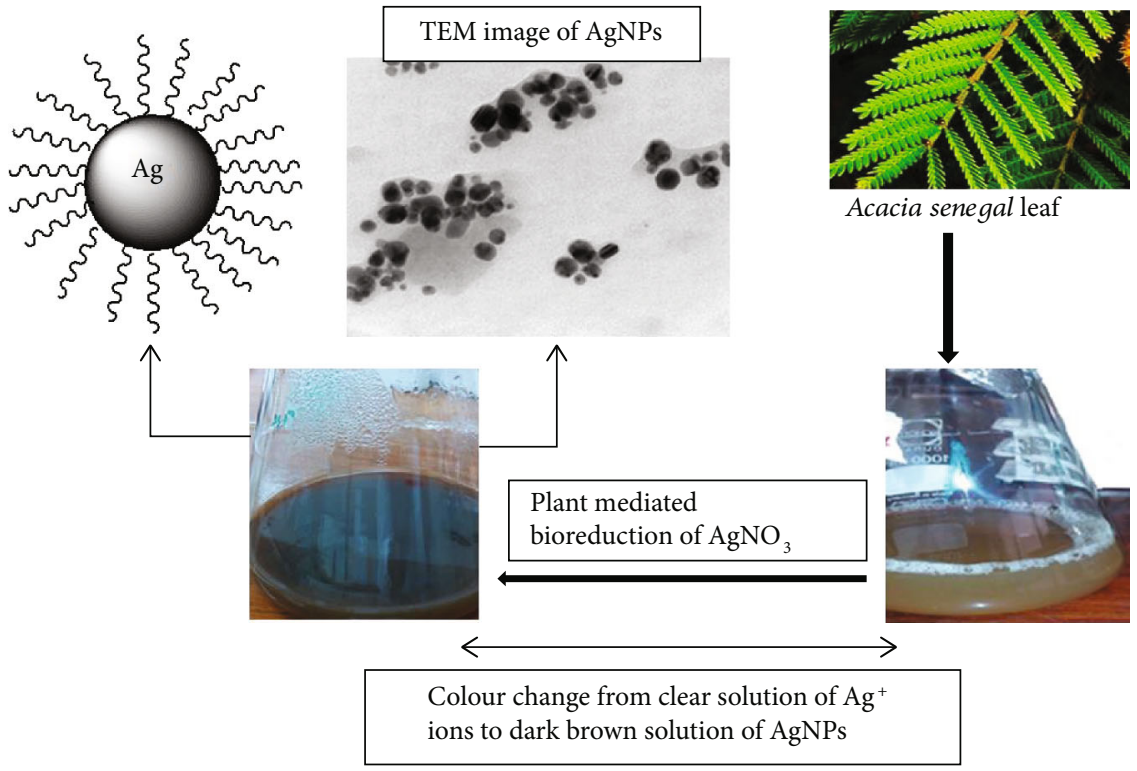

FIGURE 1: Schematic representation of the biosynthesis of silver nanoparticles from Acacia senegal leaf extract.

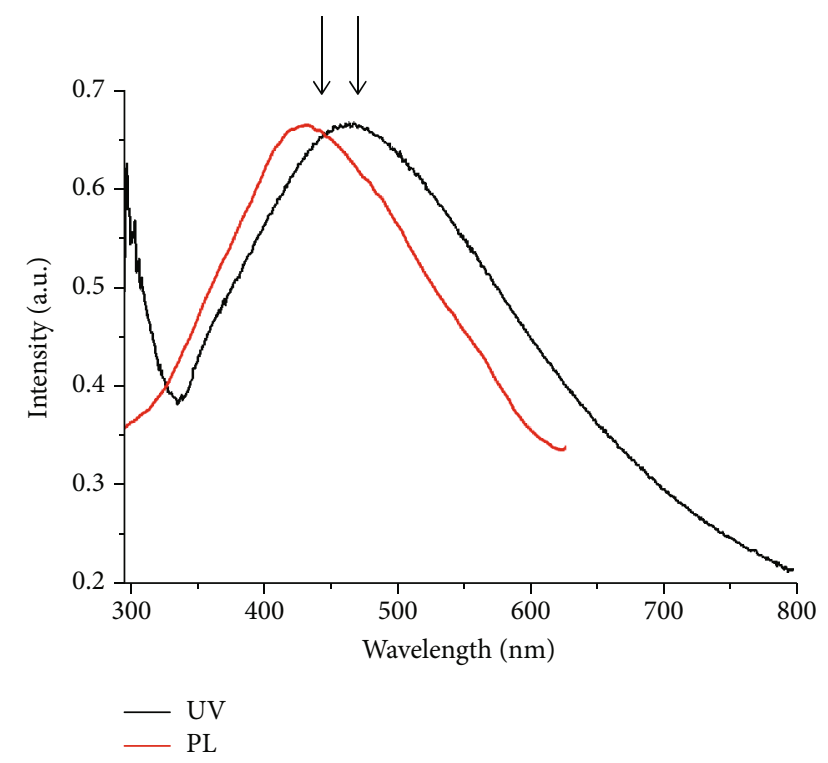

Figure 2: UV-Vis absorption and photoluminescence spectra of silver nanoparticles synthesized from Acacia senegal leaf extract.

Bragg's angle in degree [54] and corroborates well with sizes estimated from TEM images (Figure 3).

FTIR spectra (Figure 5) showed the major peaks representing the biomolecules and functional groups present in both the as-synthesized AgNPs and the leaf extract of $A$. senegal. The FTIR spectrum of the as-synthesized AgNPs (Figure 5 black) shows absorption band peak at $3319 \mathrm{~cm}^{-1}$ which is typical of phenolic compounds known for their role in preventing free radical accumulation in the body $[55,56]$. A characteristic band peak is at $1624-1631 \mathrm{~cm}^{-1}$ typical of N$\mathrm{H}, \mathrm{C}=\mathrm{O}$, and $\mathrm{C}-\mathrm{O}$ functional groups, corresponding to the amide group thus indicating the presence of tannins [55, 56]. The $1404-1414 \mathrm{~cm}^{-1}$ band is indicative of C-C stretch of the aromatic functional group. The peak at $1083 \mathrm{~cm}^{-1}$ indicates the presence of an aliphatic amine of the $\mathrm{C}-\mathrm{N}$ functional group. The results of the FTIR show that carboxyl $(-\mathrm{C}=\mathrm{O})$, hydroxyl $(-\mathrm{OH}),(\mathrm{C}-\mathrm{C})$ aromatic, and amine $(-\mathrm{NH})$ groups of the leaf extract are probably involved in the reduction and capping of the synthesized AgNPs [57]. Furthermore, the large absorbance peak observed at $3319 \mathrm{~cm}^{-1}$ and the narrow peak at $1404 \mathrm{~cm}^{-1}$ are indicative of the binding of silver ion with the hydroxyl and carboxylate groups of the Acacia senegal extract $[58,59]$.

3.2. Antimicrobial Activity Results of AgNPs on Some Selected Gram-Positive and Gram-Negative Bacteria. The AgNPs obtained from the Acacia senegal aqueous extract had very strong inhibitory action against some selected grampositive and gram-negative bacteria, and their zone of inhibition ( $\mathrm{mm}$ ) and $\mathrm{MIC}$ and $\mathrm{MBC}$ in $\mu \mathrm{g} / \mathrm{L}$ are presented in Tables 2 and 3 . Among the gram-positive bacteria (Table 2), B. cereus had the highest inhibitory activity followed by S. agalactiae, S. aureus, E. faecalis, and E. gallinarum, respectively. MBC values were the lowest in $B$. cereus while E. faecalis and E. gallinarum were greater than 10; this agrees with the work by Jain and colleagues [3] (Table 2). More so, the \% LDH release was the highest in B. cereus, $S$. aureus, S. agalactiae, and E. hirae, respectively, but was not determined in E. faecalis and E. gallinarum. B. cereus also had the highest MIC and MBC concentration and the highest $\mathrm{LDH}$ percentage. The zone of bacteria inhibition for the gram-negative bacteria (Table 3 ) showed the highest inhibitory activity in E. coli, $P$. mirabilis, and $P$. aeruginosa, respectively, and moderate inhibitory activity in K. pneumoniae, $A$. calcaoceuticals anitratus, and P. vulgaris. S. typhi showed the lowest bacterial inhibition by AgNPs. This result is in agreement with that of Kumar and colleagues [60] who reported that silver nanoparticles were fairly toxic to Pseudomonas aeruginosa while they showed moderate toxicity against $P$. 


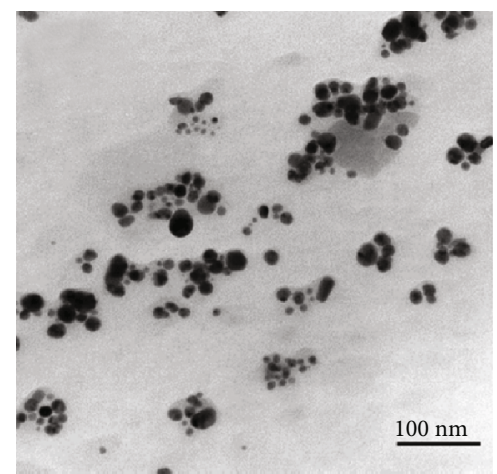

(a)

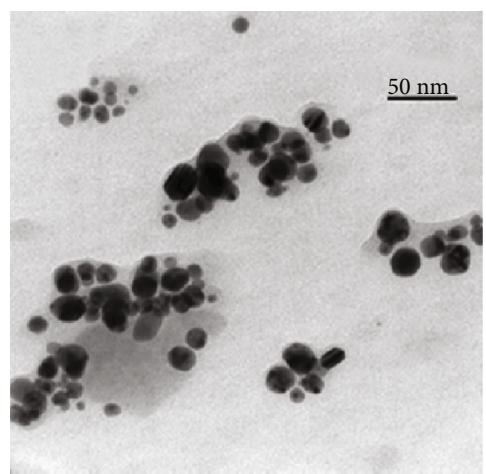

(b)

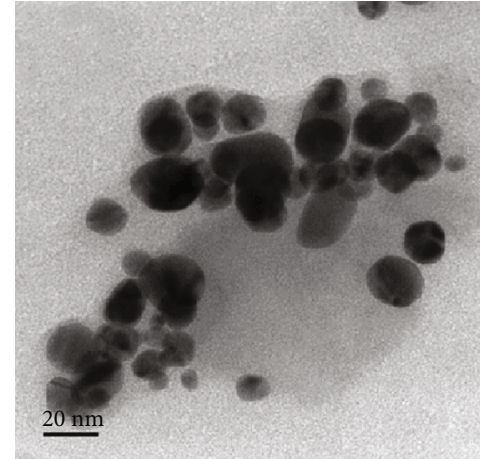

(c)

FIgURE 3: TEM micrographs of silver nanoparticles synthesized from A. senegal leaf extract at different magnifications.

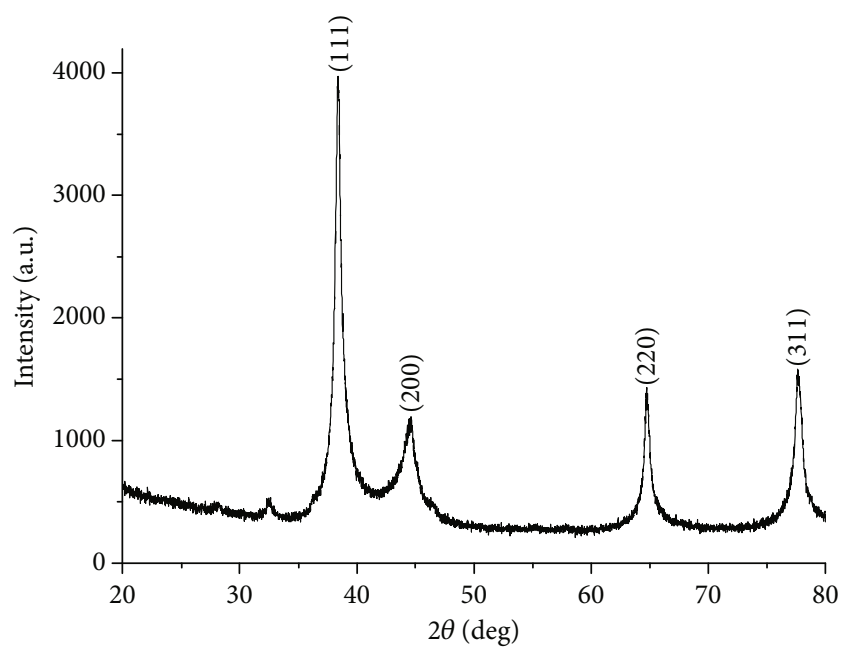

FIGURE 4: XRD pattern of silver nanoparticles synthesized from $A$. senegal leaf extract.

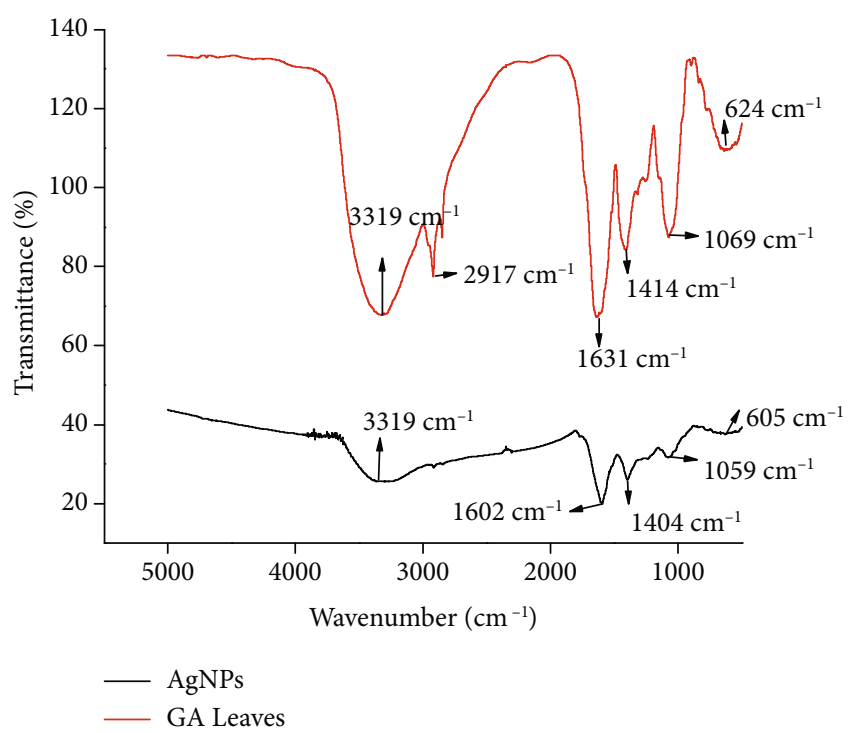

FIGURE 5: FTIR spectra of $A$. senegal leaf extract (red) and synthesized silver nanoparticles (black) using leaf extract from $A$. senegal.
TABLE 2: Antimicrobial activity test results of AgNPs on selected gram-positive bacteria.

\begin{tabular}{lcccc}
\hline $\begin{array}{l}\text { Bacteria } \\
\text { (gram positive) }\end{array}$ & $\begin{array}{c}\text { Zone of } \\
\text { inhibition }(\mathrm{mm})\end{array}$ & MIC & MBC & $\begin{array}{c}\text { \% LDH } \\
\text { release }\end{array}$ \\
\hline S. aureus & $16.45 \pm 0.34$ & 1.25 & 5 & 33 \\
S. agalactiae & $17.22 \pm 0.28$ & 0.63 & 2.5 & 17 \\
B. cereus & $18.00 \pm 1.00$ & 0.31 & 2.5 & 58 \\
E. hirae & $14.12 \pm 0.34$ & 1.25 & 5 & 7 \\
E. faecalis & $16.00 \pm 1.00$ & 5 & $>10$ & $\mathrm{ND}$ \\
E. gallinarum & $15.32 \pm 0.34$ & 2.5 & $>10$ & $\mathrm{ND}$ \\
\hline
\end{tabular}

ND: not determined.

TABLe 3: Antimicrobial activity test results of AgNPs on selected gram-negative bacteria.

\begin{tabular}{lcccc}
\hline $\begin{array}{l}\text { Bacteria } \\
\text { (gram negative) }\end{array}$ & $\begin{array}{c}\text { Zone of } \\
\text { inhibition }(\mathrm{mm})\end{array}$ & MIC & MBC & $\begin{array}{c}\% \\
\text { LDH }\end{array}$ \\
\hline E. coli & $17.76 \pm 1.06$ & 0.63 & 5 & 22 \\
P. aeruginosa & $15.00 \pm 1.00$ & 2.5 & $>10$ & $\mathrm{ND}$ \\
P. mirabilis & $16.33 \pm 0.57$ & 5 & $>10$ & $\mathrm{ND}$ \\
P. vulgaris & $11.44 \pm 0.77$ & 5 & $>10$ & $\mathrm{ND}$ \\
K. pneumoniae & $13.24 \pm 0.34$ & 2.5 & 5 & 38 \\
A. calcaoceuticals anitratus & $11.74 \pm 0.67$ & 5 & $>10$ & $\mathrm{ND}$ \\
S. typhi & $10.33 \pm 0.80$ & 5 & $>10$ & $\mathrm{ND}$ \\
\hline
\end{tabular}

ND: not determined.

vulgaris and E. coli but demonstrated low toxicity against $S$. typhi. Percentage LDH release was the highest in K. pneumoniae and was not determined in all the other organisms except E. coli. AgNPs have different antibacterial effects on the entire tested organism probably due to the difference in the constituent and the degree of thickness of the cell membrane of each bacterium [58]. This determines how the bacteria organism takes up the AgNPs which is a measure of its inhibition zone hence its antibacterial activity. The mechanism of action of silver nanoparticles as an antibacterial agent is not fully understood, but most times it can be determined by various factors including the type of species of the 
bacteria used, physical surface, chemical properties, and dimension of the AgNPs $[39,58,61]$.

\section{Conclusion}

In this study, silver nanoparticles were successfully synthesized using A. senegal aqueous leaf extract from the bioreduction of silver nitrate solution. The synthesized silver nanoparticles were confirmed and characterized using UVVis and TEM analysis while X-ray diffraction pattern confirmed the formation of the cubic phase of AgNPs. The obtained AgNPs displayed dispersion of the particles with sizes in the range of 10-19 nm, relatively small-sized particles enough for antibacterial testing. FTIR spectrum analysis of both AgNPs and leaf extract showed prominent broad band peaks that are probably responsible for effective capping and stabilizing of the silver nanoparticles. Antimicrobial studies using AgNPs showed that the nanoparticles have antibacterial activities, especially on the gram-positive bacteria. This present study established an easy, quick, and economical method to synthesize silver nanoparticles from $A$. senegal leaf extract, and this method could easily allow for industrial scale-up production of similar or other metallic nanoparticles that can be employed as a bactericidal agent in various biological applications.

\section{Data Availability}

The data used to support the findings of this study are available from the corresponding author upon request.

\section{Conflicts of Interest}

The authors declare no conflict of interest.

\section{Acknowledgments}

The support of the University of Zululand Research Committee and the National Research Foundation (NRF) is greatly acknowledged. The Chemistry Department of the University of Zululand is also acknowledged for facilitating the synthesis and characterization of AgNPs.

\section{References}

[1] G. Nam, B. Purushothaman, S. Rangasamy, and J. M. Song, "Investigating the versatility of multifunctional silver nanoparticles: preparation and inspection of their potential as wound treatment agents," International Nano Letter, vol. 6, no. 1, pp. 51-63, 2016.

[2] A. Ravindran, P. Chandran, and S. S. Khan, "Biofunctionalized silver nanoparticles: advances and prospects," Colloids and Surfaces, vol. 105, pp. 342-352, 2013.

[3] D. Jain, H. K. Daima, S. Kachhwaha, and S. L. Kothari, "Synthesis of plant-mediated silver nanoparticles using papaya fruit extract and evaluation of their antimicrobial activities," Digest Journal of Nanomaterials and Biostructures, vol. 4, no. 3, pp. 557-563, 2009.

[4] R. Veerasamy, T. Z. Xin, S. Gunasagaran et al., "Biosynthesis of silver nanoparticles using mangosteen leaf extract and evalua- tion of their antimicrobial activities," Journal of Saudi Chemical Society, vol. 15, no. 2, pp. 113-120, 2011.

[5] E. McGillicuddy, I. Murray, S. Kavanagh et al., "Silver nanoparticles in the environment: sources, detection and ecotoxicology," Science of the Total Environment, vol. 575, pp. 231-246, 2017.

[6] B. Khodashenas and H. R. Ghorbani, "Synthesis of silver nanoparticles with different shapes," Arabian Journal of Chemistry, vol. 12, no. 8, pp. 1823-1838, 2019.

[7] M. I. Skiba, V. I. Vorobyova, A. Pivovarov, and N. P. Makarshenko, "Green synthesis of silver nanoparticles in the presence of polysaccharide: optimization and characterization," Journal of Nanomaterials, vol. 2020, Article ID 3051308, 10 pages, 2020.

[8] B. Gaddala and S. Nataru, "Synthesis, characterization and evaluation of silver nanoparticles through leaves of Abrus precatorius L.: an important medicinal plant," Applied Nanoscience, vol. 5, no. 1, pp. 99-104, 2015.

[9] T. T. N. Dung, V. N. Nam, T. T. Nhan et al., "Silver nanoparticles as potential antiviral agents against African swine fever virus," Materials Research Express, vol. 6, no. 12, pp. 12501259, 2019.

[10] W. Huang, M. Yan, H. Duan, Y. Bi, X. Cheng, and H. Yu, "Synergistic antifungal activity of green synthesized silver nanoparticles and epoxiconazole against Setosphaeria turcica," Journal of Nanomaterials, vol. 2020, 7 pages, 2020.

[11] C. C. Li, S. J. Chang, F. J. Su, S. W. Lin, and Y. C. Chou, "Effects of capping agents on the dispersion of silver nanoparticles," Colloids and Surfaces A: Physicochemical and Engineering Aspects, vol. 419, pp. 209-215, 2013.

[12] A. A. Yaqoob, K. Umar, and M. N. M. Ibrahim, "Silver nanoparticles: various methods of synthesis, size affecting factors and their potential applications-a review," Applied Nanoscience, vol. 10, no. 5, pp. 1369-1378, 2020.

[13] A. Devadiga, K. V. Shetty, and M. B. Saidutta, "Timber industry waste-teak (Tectona grandis Linn.) leaf extract mediated synthesis of antibacterial silver nanoparticles," International Nano Letters, vol. 5, no. 4, pp. 205-214, 2015.

[14] M. Huq, "Green synthesis of silver nanoparticles using Pseudoduganella eburnea MAHUQ-39 and their antimicrobial mechanisms investigation against drug resistant human pathogens," International Journal of Molecular Sciences, vol. 21, no. 4, article 1510, 2020.

[15] S. Kaviya, J. Santhanalakshmi, B. Viswanathan, J. Muthumary, and K. Srinivasan, "Biosynthesis of silver nanoparticles using Citrus sinensis peel extract and its antibacterial activity," Spectrochimica Acta Part A: Molecular and Bimolecular Spectroscopy, vol. 79, no. 3, pp. 594-598, 2011.

[16] O. V. Kharissova, H. V. R. Dias, B. I. Kharisov, B. O. Pérez, and V. M. J. Pérez, "The greener synthesis of nanoparticles," Trends in Biotechnology, vol. 31, no. 4, pp. 240-248, 2013.

[17] V. V. Makarov, A. J. Love, O. V. Sinitsyna et al., "Green nanotechnologies: synthesis of metal nanoparticles using plants," Acta Naturae, vol. 6, no. 1, p. 20, 2014.

[18] M. Akter, M. T. Sikder, M. M. Rahman et al., "A systematic review on silver nanoparticles-induced cytotoxicity: physicochemical properties and perspectives," Journal of Advanced Research, vol. 9, pp. 1-16, 2018.

[19] I. Hussain, N. B. Singh, A. Singh, H. Singh, and S. C. Singh, "Green synthesis of nanoparticles and its potential application," Biotechnology Letters, vol. 38, no. 4, pp. 545-560, 2016. 
[20] A. K. Mittal, Y. Chisti, and U. C. Banerjee, "Synthesis of metallic nanoparticles using plant extracts," Biotechnology Advances, vol. 31, no. 2, pp. 346-356, 2013.

[21] S. M. Pourmortazavi, M. Taghdiri, V. Makari, and M. RahimiNasrabadi, "Procedure optimization for green synthesis of silver nanoparticles by aqueous extract of Eucalyptus oleosa," Spectrochimica Acta Part A: Molecular and Biomolecular Spectroscopy, vol. 136, pp. 1249-1254, 2015.

[22] B. Kumar, K. Smita, L. Cumbal, and A. Debut, "Green synthesis of silver nanoparticles using Andean blackberry fruit extract," Saudi Journal of Biological Sciences, vol. 24, no. 1, pp. 45-50, 2017.

[23] E. Alzahrani and K. Welham, "Optimization preparation of the biosynthesis of silver nanoparticles using watermelon and study of itsantibacterial activity," International Journal of Basic and Applied Sciences, vol. 3, no. 4, pp. 392-400, 2014.

[24] C. Buzea, I. I. Pacheco, and K. Robbie, "Nanomaterials and nanoparticles: sources and toxicity," Biointerphases, vol. 2, no. 4, pp. MR17-MR71, 2007.

[25] M. Mavaei, A. Chahardoli, Y. Shokoohinia, A. Khoshroo, and A. Fattahi, "One-step synthesized silver nanoparticles using isoimperatorin: evaluation of photocatalytic, and electrochemical activities," Scientific Reports, vol. 10, no. 1, p. 1762, 2020.

[26] K. Parveen, V. Banse, and L. Ledwani, "Green synthesis of nanoparticles: their advantages and disadvantages," AIP Conference Proceedings, vol. 1724, no. 1, article 020048, 2016.

[27] S. Ahmed, M. Ahmad, B. L. Swami, and S. Ikram, "A review on plants extract mediated synthesis of silver nanoparticles for antimicrobial applications: a green expertise," Journal of Advanced Research, vol. 7, no. 1, pp. 17-28, 2016.

[28] K. Nahar, S. Aziz, M. Bashar, M. Haque, and S. M. Al-Reza, "Synthesis and characterization of silver nanoparticles from Cinnamomum tamala leaf extract and its antibacterial potential," International Journal of Nano Dimension, vol. 11, no. 1, pp. 88-98, 2020.

[29] M. S. John, J. A. Nagoth, K. P. Ramasamy et al., "Synthesis of bioactive silver nanoparticles by a pseudomonas strain associated with the Antarctic psychrophilic protozoon euplotes focardii," Marine Drugs, vol. 18, no. 1, p. 38, 2020.

[30] M. Rai, A. Yadav, and A. Gade, "CRC 675-current trends in phytosynthesis of metal nanoparticles," Critical Reviews in Biotechnology, vol. 28, no. 4, pp. 277-284, 2008.

[31] J. L. Gardea-Torresdey, J. G. Parsons, E. Gomez et al., "Formation and growth of Au nanoparticles inside live alfalfa plants," Nano Letters, vol. 2, no. 4, pp. 397-401, 2002.

[32] B. N. Chikamai and W. B. Banks, "Gum arabic from Acacia senegal (L) Willd. in Kenya," Food Hydrocolloids, vol. 7, no. 6, pp. 521-534, 1993.

[33] M. A. Montenegro, M. L. Boiero, L. Valle, and C. D. Borsarelli, "Gum Arabic: more than an edible emulsifier," Products and Applications of Biopolymers, vol. 51, pp. 953-978, 2012.

[34] D. Yebeyen, M. Lemenih, and S. Feleke, "Characteristics and quality of gum arabic from naturally grown Acacia senegal (Linne) Willd. trees in the Central Rift Valley of Ethiopia," Food Hydrocolloids, vol. 23, no. 1, pp. 175-180, 2009.

[35] B. H. Ali, A. Ziada, and G. Blunden, "Biological effects of gum Arabic: a review of some recent research," Food and Chemical Toxicology, vol. 47, no. 1, pp. 1-8, 2009.

[36] D. Verbeken, S. Dierckx, and K. Dewettinck, "Exudate gums: occurrence, production, and applications," Applied Microbiology and Biotechnology, vol. 63, no. 1, pp. 10-21, 2003.
[37] E. O. Uzunuigbe, F. O. Osunsanmi, P. Masamba, R. A. Mosa, A. R. Opoku, and A. P. Kappo, "Phytochemical constituents and antioxidant activities of crude Extracts from Acacia Senegal leaf Extracts," Pharmacognosy Journal, vol. 11, no. 6s, pp. 1409-1414, 2019.

[38] A. Syafiuddin, Salmiati, T. Hadibarata, M. R. Salim, A. B. H. Kueh, and A. A. Sari, "A purely green synthesis of silver nanoparticles using Carica papaya, Manihot esculenta, and Morinda citrifolia: synthesis and antibacterial evaluations," Bioprocess and Biosystems Engineering, vol. 40, no. 9, pp. 1349-1361, 2017.

[39] A. Syafiuddin, Salmiati, T. Hadibarata, A. Beng Hong Kueh, and M. Razman Salim, "Novel weed-extracted silver nanoparticles and their antibacterial appraisal against a rare bacterium from river and sewage treatment plan," Nanomaterials, vol. 8, no. 1, p. 9, 2018.

[40] G. E. Trease and W. C. Evans, Pharmacognosy, Bailliere Tindall, London, 1989.

[41] J. B. Harborne, "Phenolic compounds," in Phytochemical method, pp. 33-88, Springer, 1973.

[42] K. B. H. Salah, M. A. Mahjoub, S. Ammar et al., “Antimicrobial and antioxidant activities of the methanolic extracts of threeSalviaspecies from Tunisia," Natural Product Research, vol. 20, no. 12, pp. 1110-1120, 2006.

[43] J. Eloff, "A sensitive and quick microplate method to determine the minimal inhibitory concentration of plant extracts for bacteria," Planta Medica, vol. 64, no. 8, pp. 711-713, 1998.

[44] J. D. N'guessan, M. R. Dinzedi, N. Guessennd et al., “Antibacterial activity of the aqueous extract of Thonningia sanguinea against Extended-Spectrum-b-Lactamases (ESBL) producing Escherichia coli and Klebsiella pneumoniae strains," Tropical Journal of Pharmaceutical Research, vol. 6, no. 3, pp. 779783, 2007.

[45] S. M. J. Fleiszig, M. S. F. Kwong, and D. J. Evans, "Modification of Pseudomonas aeruginosa interactions with corneal epithelial cells by human tear fluid," Infection and Immunity, vol. 71, no. 7, pp. 3866-3874, 2003.

[46] R. Güzel and G. Erdal, "Synthesis of silver nanoparticles," in Silver Nanoparticles-Fabrication, Characterization and Applications, IntechOpen, 2018.

[47] P. Banerjee, M. Satapathy, A. Mukhopahayay, and P. Das, "Leaf extract mediated green synthesis of silver nanoparticles from widely available Indian plants: synthesis characterization, antimicrobial property and toxicity analysis," Bioresources and Bioprocessing, vol. 1, no. 1, p. 3, 2014.

[48] A. Lalitha, R. Subbaiya, and P. Ponmurugan, "Green synthesis of silver nanoparticles from leaf extract Azhadirachta indica and to study its anti-bacterial and antioxidant property," International Journal of Current Microbiology and Applied Sciences, vol. 2, no. 6, pp. 228-235, 2013.

[49] D. Philip and C. Unni, "Extracellular biosynthesis of gold and silver nanoparticles using Krishna tulsi (Ocimum sanctum) leaf," Physica E: Low-dimensional Systems and Nanostructures, vol. 43, no. 7, pp. 1318-1322, 2011.

[50] D. A. Kumar, V. Palanichamy, and S. M. Roopan, "Green synthesis of silver nanoparticles using Alternanthera dentata leaf extract at room temperature and their antimicrobial activity," Spectrochimica Acta Part A: Molecular and Biomolecular Spectroscopy, vol. 127, pp. 168-171, 2014.

[51] E. K. Elumalai, T. N. Prasad, K. Venkata, P. C. Nagajyothi, and E. David, "Green synthesis of silver nanoparticle using 
Euphorbia hirta $L$ and their antifungal activities," Archives of Applied Science Research, vol. 2, no. 6, pp. 76-81, 2010.

[52] Y. Rout, S. Behera, A. K. Ojha, and P. L. Nayak, "Green synthesis of silver nanoparticles using Ocimum sanctum (Tulashi) and study of their antibacterial and antifungal activities," Journal of Microbiology and Antimicrobials, vol. 4, no. 6, pp. 103109, 2012.

[53] S. L. Smitha, K. M. Nissamudeen, D. Philip, and K. G. Gopchandran, "Studies on surface plasmon resonance and photoluminescence of silver nanoparticles," Spectrochimica Acta, Part A: Molecular and Biomolecular Spectroscopy, vol. 71, no. 1, pp. 186-190, 2008.

[54] D. S. Balaji, S. Basavaraja, R. Deshpande, D. B. Mahesh, B. K. Prabhakar, and A. Venkataraman, "Extracellular biosynthesis of functionalized silver nanoparticles by strains of Cladosporium cladosporioides fungus," Colloids and Surfaces B: Biointerfaces, vol. 68, no. 1, pp. 88-92, 2009.

[55] B. R. Ganapuram, M. Alle, R. Dadigala, A. Dasari, V. Maragoni, and V. Guttena, "Catalytic reduction of methylene blue and Congo red dyes using green synthesized gold nanoparticles capped by salmalia malabarica gum," International Nano Letters, vol. 5, no. 4, pp. 215-222, 2015.

[56] N. Rana, S. Chand, and A. K. Gathania, "Green synthesis of zinc oxide nano-sized spherical particles using Terminalia chebula fruits extract for their photocatalytic applications," International Nano Letters, vol. 6, no. 2, pp. 91-98, 2016.

[57] V. Kathiravan, S. Ravi, S. Ashokkumar, S. Velmurugan, K. Elumalai, and C. P. Khatiwada, "Green synthesis of silver nanoparticles using Croton sparsiflorus morong leaf extract and their antibacterial and antifungal activities," Spectrochimica Acta Part A: Molecular and Biomolecular Spectroscopy, vol. 139, pp. 200-205, 2015.

[58] M. M. H. Khalil, E. H. Ismail, and F. El-Magdoub, "Biosynthesis of Au nanoparticles using olive leaf extract," Arabian Journal of Chemistry, vol. 5, no. 4, pp. 431-437, 2012.

[59] M. M. H. Khalil, E. H. Ismail, K. Z. El-Baghdady, and D. Mohamed, "Green synthesis of silver nanoparticles using olive leaf extract and its antibacterial activity," Arabian Journal of Chemistry, vol. 7, no. 6, pp. 1131-1139, 2014.

[60] P. Kumar, S. S. Selvi, A. L. Prabha, K. P. Kumar, R. S. Ganeshkumar, and M. Govindaraju, "Synthesis of silver nanoparticles from Sargassum tenerrimumand screening phytochemicals for its antibacterial activity," Biomedical Engineering Nanoscience and anotechnology, vol. 4, no. 1, pp. 12-16, 2012.

[61] A. N. Aini, D. A. Al Farraj, E. Endarko et al., "A new green method for the synthesis of silver nanoparticles and their antibacterial activities against gram-positive and gram-negative bacteria," Journal of the Chinese Chemical Society, vol. 66, no. 7, pp. 705-712, 2019. 